\title{
Dificuldades do associativismo municipal em Minas Gerais: Reflexões a partir de um estudo de caso
}

\author{
Aline Werneck Barbosa de Carvalho \\ Mestre pela FAUUSP. Professora do Departamento de \\ Arquiteura e Urbanismo da Universidade de Viçosa - MG \\ Doutoranda na FAUUSP, sob orientação do Prof. Carlos \\ Eduardo Zahn
}

Resumo Considerações sobre uma estratégia de planejamento microrregional implantada no estado de Minas Gerais no período 19741987, denominada associativismo municipal. Discussão das principais dificuldades que envolvem a execução desta estratégia numa porção específica do estado: A microrregião da zona da mata norte.

Abstract

Introdução

(1) Estas conclusōes foram apresentadas na dissertaçāo de mestrado intitulada A implantação do associativismo municipal na microrregião da zona da mata norte de Minas Gerais, no período de 1985 a 1994: Dificuldades de uma estratégia de planejamento microrregional, defendida junto à FAUUSP em novembro de 1995, sob orientaçāo acadêmica do Prof. Dr. Carlos Eduardo Zahn
This article presents a regional planning strategy called Associativismo Municipal, that has been established in the state of Minas Gerais/Brazil since 1974, and analyses some difficulties related to its performance in a small region of the state - the microrregião da zona da mata norte.

Este artigo tem por objetivo apresentar algumas dificuldades que envolvem a execução de uma estratégia de planejamento microrregional, denominada associativismo municipal, numa porção específica do estado de Minas Gerais: a microrregião da zona da mata norte ${ }^{1}$

O associativismo municipal foi implantado em Minas Gerais em 1974, através do Programa de Desenvolvimento Microrregional PRODEMI e da criação da primeira Associação Microrregional de Municípios (Associação dos Municípios da Microrregião do Vale 
do Aço (AMVA). A partir daí, até o ano de 1987, o programa foi paulatinamente implantado em todo o estado que, hoje, encontrase subdividido em 37 microrregiões com suas respectivas associações municipais. Dentre elas, a Associação de Municípios da Microrregião da Zona da Mata Norte (AMMAN) foi uma das últimas associações criadas em Minas Gerais, tendo sido instalada no ano de 1985.

A extensão territorial e a diversidade geográfica, econômica e cultural do estado de Minas Gerais impedem uma generalização dos resultados, obtidos a partir do estudo realizado para a microrregião da zona da mata norte e sua respectiva associação municipal (AMMAN), para o restante das associações microrregionais de municípios do estado. Porém, sendo a associação estudada uma das mais bem equipadas do estado, acredita-se que algumas das conclusões relativas a ela possam ser estendidas a outras associações municipais mineiras, sem grande margem de erro.

Antes, porém, de passar ao tema central deste artigo, procura-se apresentar ao leitor um breve relato sobre o associativismo mineiro, suas finalidades e particularidades, de modo a possibilitar a perfeita compreensão dos aspectos apontados, posteriormente, como dificuldades responsáveis pela sua implantação e execução na microrregião da zona da mata norte.

Entende-se por Associativismo Municipal uma forma de cooperação onde os municípios se associam para se articularem entre si e com outros níveis de governo, visando ao fortalecimento de suas gestões e ao desenvolvimento socioeconômico das regiões. As associações microrregionais de municípios constituem, por sua vez, uma reunião de municípios de uma determinada região ou área socioeconômica, com o objetivo de promover a realização de serviços comuns visando o desenvolvimento municipal e microrregional.

De uma forma geral, o associativismo municipal abrange os convênios, os consórcios intermunicipais, as comissões de desenvolvimento ou quaisquer formas de associação intermunicipal. Todas estas são formas administrativas tradicionais utilizadas na tentativa de solucionar problemas que transcendem as fronteiras de uma só administração municipal. Na prática, estas

$O$ associativismo municipal em Minas Gerais: o que é e o que pretende 


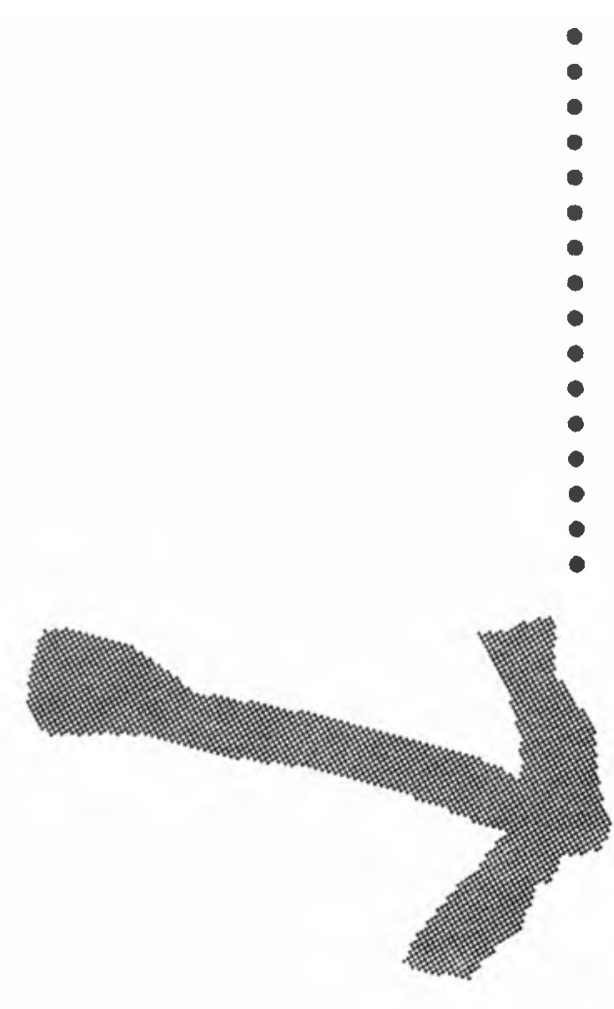

formas administrativas diferem quanto ao aspecto jurídico e quanto ao âmbito de atuação. Quanto ao aspecto jurídico podem assumir a forma de entidade civil sem fins lucrativos, fundação ou mesmo empresa pública; quanto ao âmbito de atuação, podem ser setorial ou geral - são setoriais quando suas atividades são limitadas a uma única função e gerais quando possuem objetivos mais abrangentes como, por exemplo, tratar de problemas comuns aos municípios de uma microrregião, visando a promoção do seu desenvolvimento ${ }^{2}$.

No caso específico do associativismo em Minas Gerais, "as associações de municipios constituem congregações de municípios, espacialmente contíguos, dos quais um é a sede (normalmente o município que já exerce uma certa polarização sobre os demais), com determinada forma institucional e estatutária, cujo objetivo principal é a busca de soluções para problemas de natureza comum, nas áreas administrativa, econômica, social, política e físico-territorial"3.

(2) TAVARES, Hermes. Planejamento microrregional e consórcios intermunicipais. Revista de Administração Municipal, v. 24, n. 144 p. $53-64$, set./out. 1977 , p. 58

(3) ARANTES, Paulo Tadeu L. A experiência mineira em articulação, assistência técnica e assessoramento a seus municipios através do associativismo municipal, a partir de 1974. São Paulo, 1990 (Dissertaçāo de Mestrado). p. 79

(4) Segundo MEIRELLES (1985) assim como os convênios, os consórcios não têm personalidade jurídica e dependem de autorização legislativa e de recursos financeiros para atendimento dos encargos assumidos nos termos da cooperação.

(No entanto, algumas ressalvas devem ser feitas quanto aos consórcios intermunicipais paulistas que, como as associações múnicipais mineiras, possuem personalidade jurídica).

(5) De acordo com a "Minuta de Anteprojeto de Estatuto de uma Associaçāo Microrregional de Municipios" (SEAM, out./1992, p. 21) às fontes de recursos financeiros citadas, somam-se as seguintes dotações: produtos de operaçōes de créditos; recursos provenientes de suas receitas industrial, patrimonial $e$ diversas; doações e legados e, ainda, recursos eventuais que lhes forem atribuídos.

Diferentemente dos consórcios intermunicipais de municípios ${ }^{4}$, as associações microrregionais de municípios em Minas Gerais são entidades civis sem fins lucrativos, dotadas de personalidade jurídica, e, portanto, dependentes de recursos próprios para sobreviver e executar as ações que lhes competem. Possuem, assim, estatuto, receita e estrutura administrativa próprios. Sua receita é oriunda, principalmente, de um percentual das receitas dos municípios associados que, juntamente com recursos consignados nos orçamentos estadual e federal, contribuem para formar um fundo destinado a gerir as necessidades da microrregião ${ }^{5}$ Além disso, as associações municipais mineiras são de duração indeterminada e não se vinculam a uma determinada atividade.

Do ponto de vista espacial, as associações municipais em Minas Gerais se assentam sobre uma base físico-territorial que constitui a microrregião. É importante frisar a distinção entre a associação municipal e a microrregião: esta constitui a base física e espacial de uma entidade civil que é a associação intermunicipal, servindo para limitar seu âmbito territorial de ação. A constituição de cada associação e de sua respectiva base físico-territorial deu-se por iniciativa de prefeitos que, convictos das vantagens da cooperação intermunicipal, se mobilizavam em favor da criação da associação. Os limites da microrregião, por sua vez, não foram definidos por 
critérios técnicos, mas levaram em consideração a área polarizada por uma cidade que desempenhava certo grau de influência sobre os municípios a sua volta, então chamada de cidade-pólo microrregional.

A delimitação espacial da área de atuação de cada associação municipal mineira deu origem à divisão do território estadual em microrregiões que constituem, portanto, a base territorial da estratégia associativista no estado (Figura 1).

\section{ESTADO DE MINAS GERAIS}

Microrregiões da zona da mata norte em relação às associações microrregionais de municipios

Fonte: Elaborado pela autora a partir de dados da SEAM/MG e da AMMAM

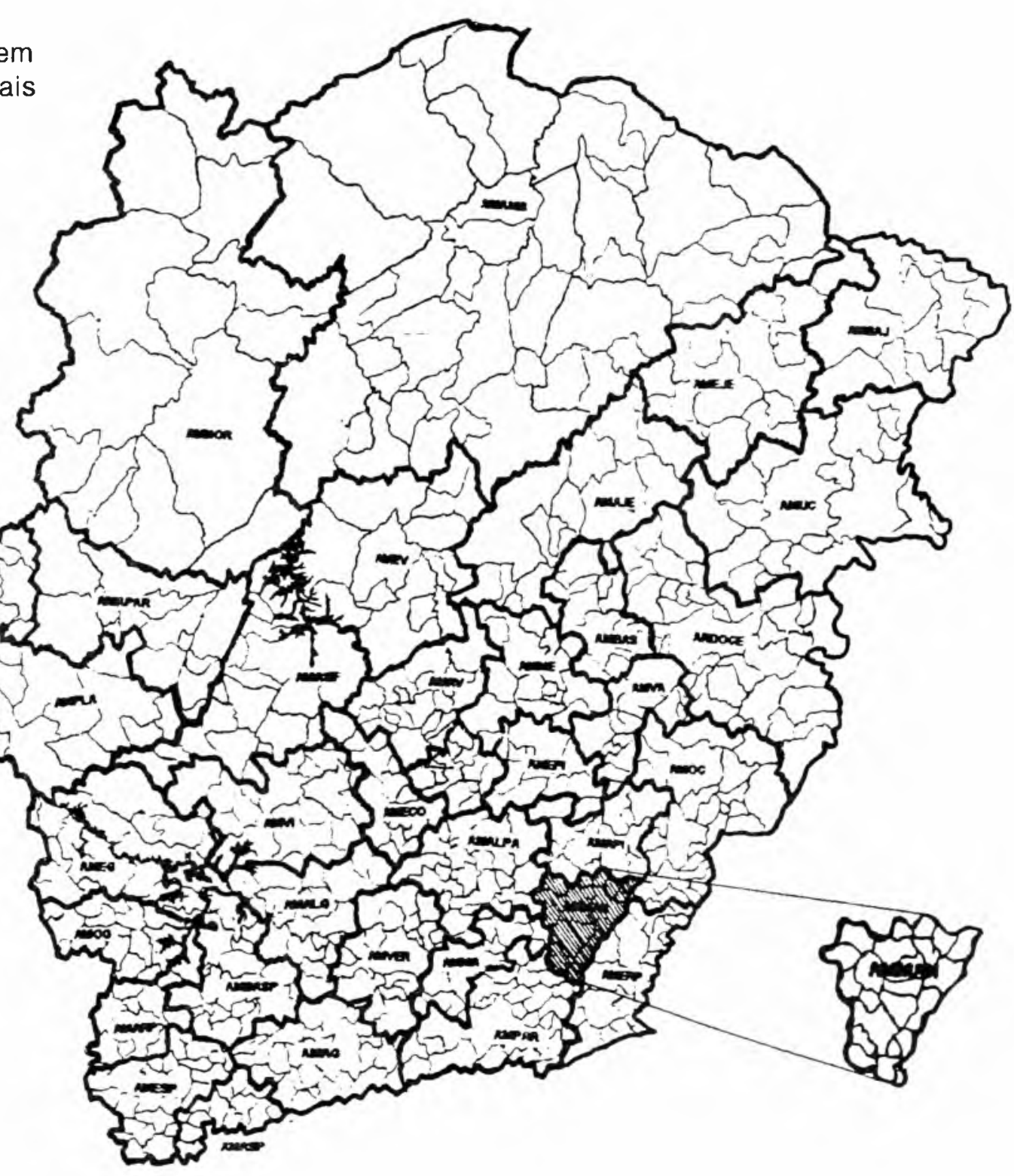

Figura 1 - Mapa das microrregiões do associativismo municipal e da AMMAN -

Associaçāo de Municipios da Microrregião da Zona da Mata Norte / Minas Gerais (1993) 
As primeiras experiências em termos de associativismo municipal no Brasil surgiram na década de 60 , a partir de iniciativas isoladas de âmbito estadual ou local, nos estados de São Paulo, Santa Catarina e Rio Grande do Sul. Em Minas Gerais, porém, o associativismo municipal não surgiu de forma espontânea, tendo sido induzido através de programas específicos da Superintendência de Articulação com os Municípios (Supam) - órgão criado pelo governo estadual visando a articulação intergovernamental.

De fato, comparando-se o associativismo municipal em Minas Gerais com as primeiras experiências associativistas ocorridas em Santa Catarina e no Rio Grande do Sul, desde o início da década de 60 , verificaremos uma importante diferença entre elas, embora tenham ocorrido dentro do mesmo contexto histórico e político nacional. Esta diferença reside, sobretudo, na forma como se deu o processo de aglutinação intermunicipal.

Sem dúvida, os estados de Santa Catarina e do Rio Grande do Sul se anteciparam às iniciativas do governo federal que, preocupado com a escala das grandes regiões, privilegiava em seus planos, não só os aspectos econômicos do planejamento, como também a abordagem da questão regional, sob o ponto de vista da macrorregião. Enquanto a preocupação com questões relativas à rede urbana e ao planejamento urbano e microrregional nasceu com o Serviço Federal de Habitação e Urbanismo (Serfau), em 1964, em alguns estados os desníveis regionais já vinham sendo tratados como uma preocupação estadual e, em muitos casos, até municipal. Em outras palavras, na ausência de efetiva atuação dos governos federal e estadual para promover o desenvolvimento dos municípios e das microrregiões, aos poucos foram surgindo iniciativas das próprias municipalidades no sentido de conjugarem esforços visando a solução de problemas comuns, surgindo assim várias entidades associativas intermunicipais ${ }^{6}$ Mesmo que, a partir de 1968, se possa registrar a ação indutiva da Superintendência de Desenvolvimento da Região Sul (Sudesul), no sentido de motivar a organização de associações municipais, na maioria dos casos o processo de aglutinação municipal nos estados sulinos

(6) TAVARES, Hermes, op. cit., p. 54-55.

(7) CORNELY, Seno A. Evoluçāo do planejamento urbano e local no Brasil perspectiva microrregional. Rev. Planejamento, v. 4, n. 2, p. 97-113 abr./dez. 1976. p. 108 e 109 foi bastante espontâneo, não seguindo critérios técnicos predeterminados $^{7}$

O caso do associativismo municipal mineiro é, sem dúvida, diferente. Embora se reconheça a necessidade de cooperação 
entre os municipios, visando ao seu fortalecimento político, financeiro e institucional, não se pode negar a participação governamental na implantação da estratégia associativista no estado. Mais que isto, não se pode negar a antecipação dos governos federal e estadual em relação às iniciativas das municipalidades mineiras.

Segundo Dutra \& Pires, "o cenário maior do qual emerge o apoio à criação de associações de municípios em Minas Gerais é o do processo de modernização levado a cabo pelos governos revolucionários pós-64" Segundo os autores, "pretendia-se a execução de um modelo de planejamento centralizado, com instrumentos técnicos e financeiros capazes de trazer estados e municípios para um caminho único traçado pela tecnocracia da União" 8 associativismo municipal seria um desses instrumentos.

Como afirma Arantes (1991), pensado como mecanismo intermediário de planejamento, o associativismo municipal em Minas Gerais representava mais do que a simples agregação de municípios, objetivando a articulação intermunicipal e com outros níveis de governo, tendo em vista o desenvolvimento municipal e microrregional. Representava, portanto, uma estratégia de planejamento regional e um importante instrumento para o governo centralmente constituído, na medida em que se propunha a participar do esforço de articulação entre os diversos níveis de governo - federal, estadual e municipal -, estabelecendo não só uma ponte entre os municípios e outras esferas de poder, mas sobretudo, facilitando a implementação de planos, programas e projetos do governo federal no interior do estado.

O primeiro esforço realizado pelo governo federal no sentido de promover a articulação intergovernamental correspondeu à criação da Secretaria de Articulação entre Estados e Municípios (Sarem) vinculada à Secretaria de Planejamento da Presidência da República. Através da criação desta secretaria, pretendia-se estimular a criação de órgãos similares no âmbito dos sistemas de planejamento dos estados, a quem caberia incentivar a criação de associações de municípios. Estas, por sua vez, deveriam funcionar como "instâncias intermediárias de coordenação da execução de programas e projetos de interesse da União e dos Estados"9

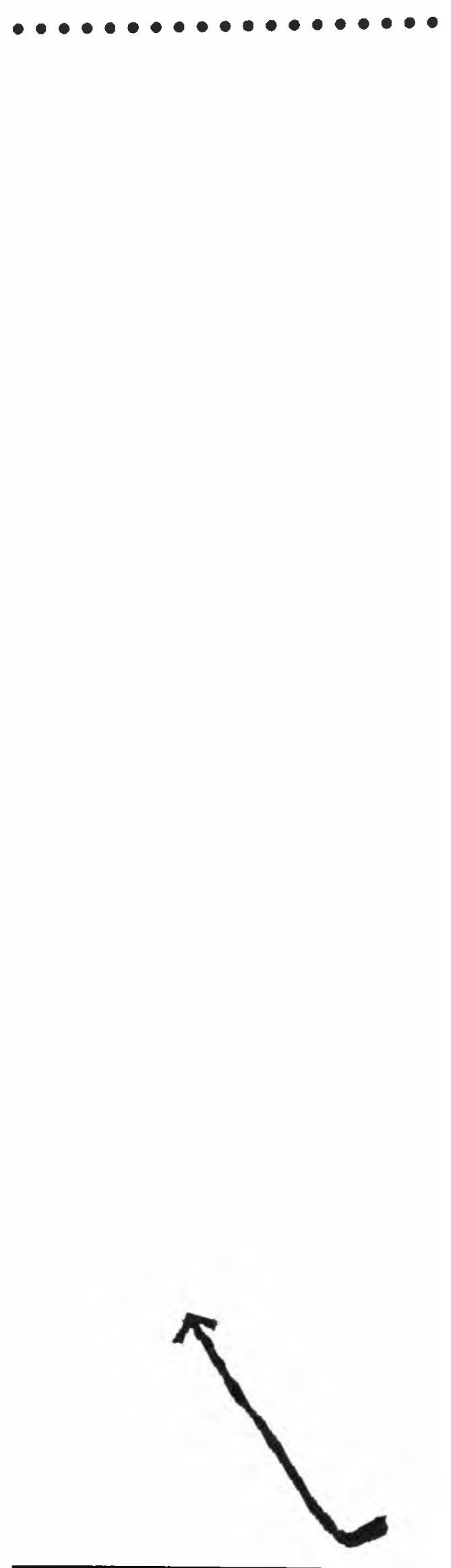

(8) DUTRA, Heraldo S., PIRES, Maria Coeli C. O Associativismo Municipal em Minas Gerais e a presença do Estado. In: $O$ associativismo estratégico, p. 4.

(9) Ibidem, p. 4 
Os objetivos da Sarem encontraram, no estado de Minas Gerais, as condições necessárias para o estabelecimento da articulação intergovernamental. De fato, o início da década de 70 correspondeu à institucionalização das atividades de planejamento no estado e à criação do Sistema Estadual de Planejamento. O apoio institucional representado pela estrutura administrativa foi fundamental para a introdução do associativismo municipal no estado de Minas Gerais, já que a implantação desta estratégia apoiava-se na existência de uma instância de planejamento estadual que pudesse estabelecer a ponte entre os governos estadual e federal, permitindo a articulação almejada.

Assim, em 1973, o governo mineiro criou a Superintendência de Articulação com os Municípios (Supam), vinculada inicialmente ao Conselho Estadual de Desenvolvimento (CED), posteriormente à Secretaria do Estado de Planejamento e Coordenação Geral (Seplan/MG) e, atualmente, à Secretaria de Estado de Assuntos Municipais (Seam/MG). A principal finalidade deste órgão era articular o planejamento municipal e microrregional com o planejamento estadual, bem como prestar assistência técnica aos municípios mineiros.

A criação da Supam representou o passo institucional necessário para a implantação da estratégia associativista mineira, introduzida através de um dos programas básicos dessa superintendência o Programa de Desenvolvimento Microrregional (Prodemi) $)^{10}$ - cujo objetivo consistia em executar um processo de planejamento microrregional, atingindo os municípios por meio de associações microrregionais.

É importante destacar, portanto, que o processo de criação das associações municipais mineiras correspondeu também à implantação do planejamento microrregional no estado. A microrregião se tornou a base territorial das associações municipais, isto é, do conjunto de municípios que, agrupados em torno de um pólo, se reuniria em uma entidade associativa com o objetivo de solucionar os problemas locais e extralocais.

Implantadas como estratégias de planejamento microrregional destinadas a participar do esforço empreendido, em nível federal e estadual, no sentido de reduzir os desequilíbrios 
regionais, as associações microrregionais de municípios têm como principal objetivo propiciar o fortalecimento da capacidade administrativa, econômica e social dos municípios associados utilizando como instrumentos a articulação intergovernamental e a prestação de assistência técnica aos municípios associados. Estas atividades envolvem a prestação, pela associação, de uma série de serviços tais como: serviços de engenharia (obras e projetos em geral), atividades de treinamento de pessoal técnico e administrativo, melhoria das estradas vicinais, serviços de terraplenagem, nivelamento e outros, além da possibilidade de realização de convênios de interesse dos municípios.

As primeiras associações mineiras foram definitivamente implantadas a partir da instalação da Associação de Municípios da Microrregião do Vale do Aço (AMVA), em julho de 1974. O processo de implantação não se deu imediatamente, mas no decorrer de 13 anos, ocorrendo até um período em que praticamente não houve formação de novas associações, devido à própria conjuntura política estadual. A última associação Associação de Municípios da Microrregião do Médio Centro-Oeste (AMECO) - foi instalada em 1987, ficando o estado subdividido em 36 microrregiões com suas respectivas associações. Atualmente, após a subdivisão da Associação dos Municípios da Microrregião do Vale do Rio Grande (AMGRA) em duas associações, Associação de Municípios da Microrregião do Vale do Rio Grande (AMVALE) e Associação de Municípios de Microrregião do Baixo Vale do Rio Grande (AMBAV), o estado de Minas Gerais se encontra subdividido em 37 associações microrregionais, além do complexo urbano formado pelos municípios da Região Metropolitana de Belo Horizonte.

Durante o período compreendido entre a instalação da primeira e da última associação municipal, o associativismo mineiro passou por fases distintas, refletindo as diferentes diretrizes, federais ou estaduais, estabelecidas a partir da Política Nacional de Desenvolvimento Urbano e Regional (PNDUR).

Hoje, diante das mudanças ocorridas em função do processo de transição democrática, marcada pela crise do planejamento e, ainda, diante da política de descentralização prevista nos textos constitucionais - federal e estadual - que ampliam a autonomia municipal e conferem maiores poderes e atribuições aos governos 
locais, a avaliação da estratégia associativista assume contornos muito interessantes. De fato, ao ampliar a autonomia dos municípios, a Constituição Federal de 1988 recoloca a questão das associações e dos consórcios intermunicipais sob novo prisma: a possibilidade de usá-los como instrumentos de descentralização administrativa e de gestão do planejamento regional.

Foi assim que, em 1991, propôs-se no âmbito do sistema estadual de planejamento, a criação de um programa destinado a promover o fortalecimento dos municípios mineiros. Este programa, denominado Prodemu - Programa Permanente de Desenvolvimento Municipal1 ${ }^{11}$ - tinha como propósito implementar a descentralização político-administrativa prevista nos textos constitucionais, utilizando como principal estratégia o associativismo municipal. Acreditavam os técnicos dos órgãos encarregados de sua articulação e execução, que do fortalecimento da estratégia associativista, das linhas programáticas, da estrutura administrativa e da própria metodologia de implementação propostas pelo Prodemu resultaria um "novo associativismo": autônomo, auto-sustentado e sintonizado com as políticas públicas do estado e da União. No entanto, apesar dos esforços realizados pelos técnicos dos órgãos de planejamento do estado, o Prodemu não tem gerado os resultados esperados.

Enfim, o associativismo municipal tem sido adotado como estratégia de planejamento microrregional no estado de Minas Gerais em dois momentos históricos distintos: num primeiro momento, que corresponde à sua criação e implantação no estado, o associativismo serviu como instrumento ao governo centralmente constituído, visando articular os três níveis governamentais - federal, estadual e municipal - dentro do conceito do planejamento global, adotado na década de 70; num segundo momento, correspondente às mudanças desencadeadas pelo processo de abertura política e pelo processo de descentralização político-administrativa previsto nos textos constitucionais, a questão das associações municipais apresenta-se sob um novo prisma: a possibilidade de usá-las como instrumentos de descentralização administrativa e de gestão do planejamento regional. 
A microrregião da zona da mata norte se localiza na parte central da região da zona da mata de Minas Gerais, compreendendo um total de 24 municípios. De uma forma geral, mantém as características comuns da região, uma das mais antigas e tradicionais do estado de Minas Gerais, cujo processo de ocupação econômica baseou-se na pecuária e na cafeicultura que ali penetrou a partir das margens do rio Paraíba. Embora tenha desempenhado papel de relevo na economia do estado até as duas primeiras décadas do século atual, devido, especialmente, às plantações de café e ao surgimento das indústrias têxtil e alimentícia, a zona da mata vem passando por um processo de declínio econômico que perdura desde a década de 60.

Assim como todas as microrregiões do associativismo municipal, a microrregião da zona da mata norte surgiu em função da criação da sua respectiva associação microrregional de municípios - a Associação de Municípios da Microrregião da Zona da Mata Norte (AMMAN). Desde sua criação, em 1985, o número de municípios associados à AMMAN vem variando em torno de 15 , ou seja, apesar da base territorial da associação ser constituída por um total de 24 municípios, o número de associados é variável, uma vez que os municípios não são obrigados a se associarem, podendo associar-se ou desligar-se da associação quando for de seu interesse.

Ainda que os resultados da pesquisa realizada na microrregião da zona da mata norte tenham demonstrado a necessidade de um instrumento capaz de propiciar o fortalecimento técnicoadministrativo e institucional dos governos locais, as conclusões apresentadas apontam sérias dificuldades que envolvem a execução da estratégia associativista na microrregião, interferindo no seu desempenho como efetivo instrumento de planejamento regional.

Estas dificuldades podem ser agrupadas, basicamente, sob três itens: a fragilidade política e financeira das associações; o desinteresse dos dirigentes municipais por atividades relativas ao planejamento e à organização dos serviços públicos municipais e a falta de espírito associativista.

De fato, a principal dificuldade encontrada pela AMMAN para atingir seu principal objetivo, qual seja, propiciar o fortalecimento da capacidade administrativa, econômica e social dos municípios

\section{As dificuldades do associativismo municipal na microrregião da zona da mata norte de Minas Gerais}

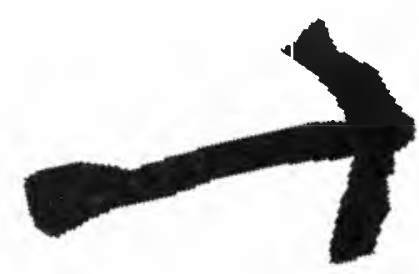


associados e o desenvolvimento de sua microrregião, reside na sua própria fragilidade política e financeira. Constituída como entidade civil autônoma, padece, tal como seus associados, da falta de recursos financeiros para investir no desenvolvimento municipal e microrregional. Assim, as associações municipais reproduzem - em nível microrregional - as dificuldades de seus membros associados, isto é, dos pequenos municípios que, embora politica e administrativamente autônomos, carecem de real autonomia financeira que lhes permitam exercer com eficiência suas obrigações relativas ao desenvolvimento municipal.

A fragilidade financeira da AMMAN fica evidente, tanto nas atas das assembléias, quanto na pesquisa de campo realizada junto aos técnicos do sistema estadual de planejamento e aos prefeitos. O agravamento da situação financeira dessa associação e, provavelmente, da maioria das associações municipais mineiras, já que a AMMAN é considerada uma das melhores do estado, pode ser atribuído a três fatores:

- baixa contribuição dos municípios associados;

- alto custo de manutenção dos equipamentos pertencentes à patrulha motomecanizada, importante fonte de complementação da receita das associações municipais;

- falta de apoio do estado.

Sem condições de auto-sustentabilidade e sem o apoio do governo estadual, a sobrevivência das associações fica, constantemente, ameaçada. As dificuldades financeiras conduzem ao não atendimento das demandas municipais o que, por sua vez, gera insatisfação entre os municípios associados. Insatisfeitos, alguns municípios se afastam da associação, reduzindo-se o número de associados e, conseqüentemente, a receita da entidade, agravando-se ainda mais a situação anterior. Isto gera mais descrédito entre os municípios e, num círculo vicioso, as associações municipais se tornam cada vez menos capazes de demonstrar para os municípios a importância da cooperação intermunicipal como um meio eficiente para suprir as deficiências municipais e fazer chegar aos governos federal e estadual as necessidades municipais e microrregionais. Este ciclo pode ser esquematizado de acordo com o Quadro 1 


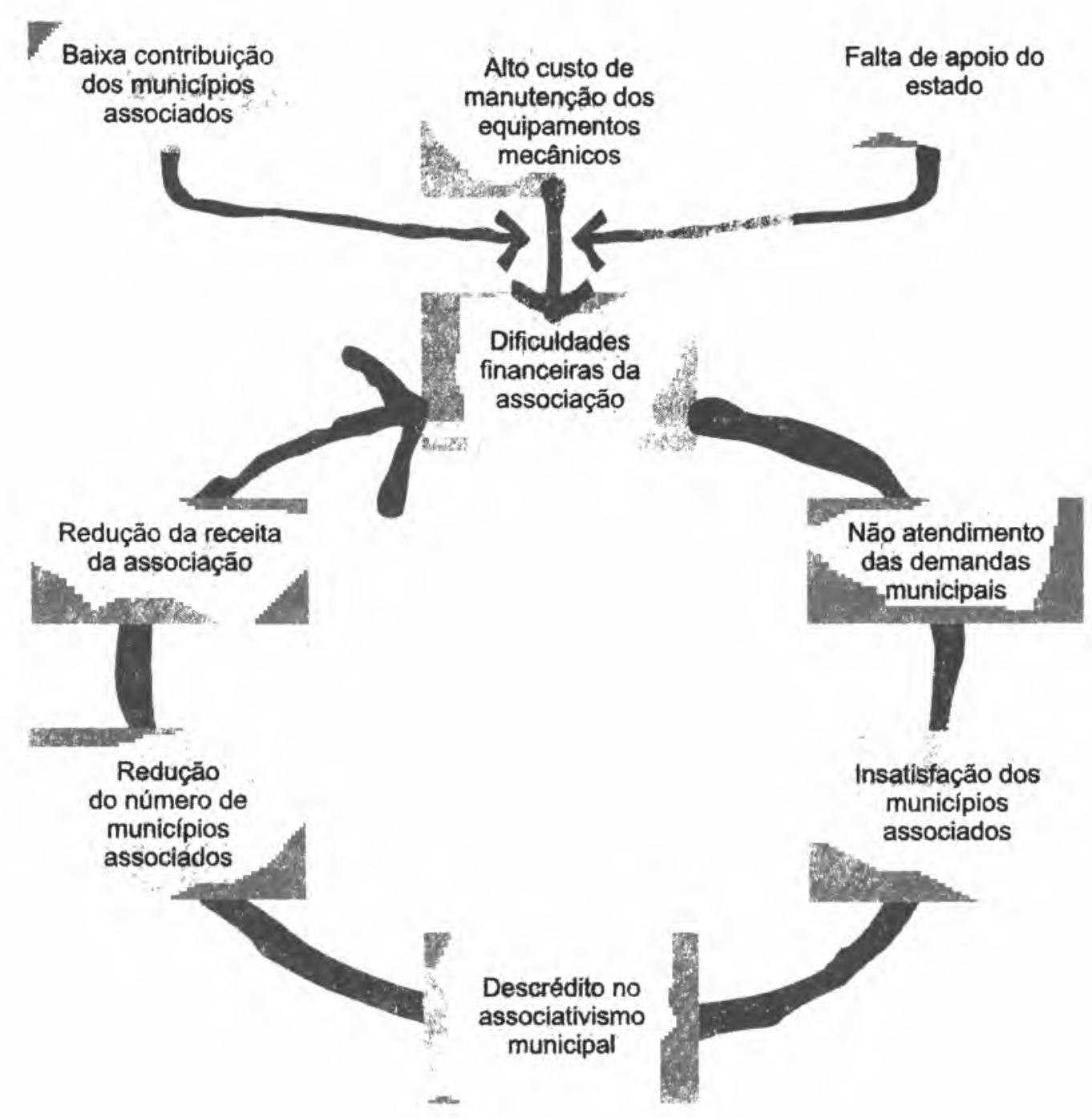

A fragilidade política da associação deve-se, por sua vez, a falta de real apoio do estado à estratégia associativista. A crescente falta de apoio do estado fica visivel através de fatos e situações concretos. Inicia-se a partir da década de 80 , devido à alteração da ênfase conferida pelas diretrizes da política estadual de planejamento em relação ao planejamento microrregional. Embora no início dessa década tivessem sido criados importantes programas de complementação da ação do associativismo municipal $^{12}$, o apoio financeiro da União e do estado para a implementação destas estratégias teve curta duração. Deste modo, quando a AMMAN foi criada, as principais linhas de ação programáticas das associações municipais haviam sido extintas ou não mais contavam com recursos financeiros dos governos federal ou estadual.

No caso do Programa de Patrulhas Motomecanizadas - Promoto ${ }^{13}$, o apoio do estado restringiu-se à doação (por meio do regime de comodato ou através de convênios), de equipamentos mecânicos

\section{Quadro 1 \\ AMMAN \\ Ciclo de dificuldades \\ da AMMAN (1985-1994)}

Fonte: autora

(12) Como o Programa de Escritórios de Engenharia - PROENG; 0 Programa de Treinamento de Administraçāo Municipal - PTAM e o Programa de Patrulhas

Motomecanizadas - PROMOTO.

(13) Este programa tem por finalidade ampliar e melhorar a malha viária dos municípios permitindo aos produtores escoamento regular de sua produçāo $\theta$ o acesso de insumos necessários, bem como possibilitar a utilizaçāo de maquinário nas atividades agrícolas, tudo coordenado pelas associaçōes. 
tais como motoniveladoras, escavadeiras, tratores de esteira e tratores agrícolas. Apesar de ser considerado o "carro-chefe" das associações municipais mineiras, na atualidade, a falta de apoio para a manutenção ou troca destes equipamentos pode acarretar o fracasso da estratégia associativista, considerandose que o Promoto representa uma importante fonte de complementação orçamentária para as associações. De fato, os serviços prestados pelo Promoto constituem uma das poucas atividades remuneradas da AMMAN, mesmo que praticada a preços inferiores ao do mercado.

A falta de apoio efetivo do estado ao associativismo mineiro fica também patente a partir da análise do Prodemu. Instituído como decreto, em 1991, com a finalidade de propiciar o fortalecimento dos municípios através do associativismo, tendo em vista a proposta de descentralização político-administrativa do governo estadual eleito, este instrumento não passou de um ato político, servindo para iludir os planejadores e as lideranças políticas locais, confiantes que estavam no despertar de uma "nova era" para o planejamento municipal e regional. Apesar de ter sido proposto com o objetivo "explícito" de fortalecer os governos locais, através do associativismo municipal, este programa está desativado.

Criado como "Programa Especial de Governo", o Prodemu privilegiou, no discurso formal, as suas linhas de ação programáticas. Estas, por sua vez, repetiram antigas estratégias ${ }^{14}$ numa tentativa de obter o apoio do estado para mecanismos cuja eficácia fora comprometida no passado. Porém, sem contar com a alocação de recursos financeiros por parte do governo estadual, o Prodemu não obteve apoio, nem dos secretários executivos das associações, nem dos prefeitos, para a implementação das linhas de ação programáticas propostas, dificultando a ação da própria Fundação João Pinheiro, constituída como seu agente técnico. Estes fatos demonstram a pouca importância conferida ao associativismo municipal, nos dias atuais, apesar do discurso formal apresentá-lo como importante estratégia de apoio ao processo de descentralização político-administrativa proposto pelo estado.

(14) Como as do Programa de Escritórios de Engenharia - PROENG e do Programa de Treinamento de Administração Municipal - PTAM.

A própria criação da Secretaria de Estado de Assuntos Municipais (SEAM), apresentada como iniciativa do governo estadual no sentido de fortalecer o município mineiro, contribuiu para se esvaziar de 
importância as associações municipais. De fato, diante do fortalecimento da estrutura técnica e administrativa desta secretaria, muitas atribuições das associações ${ }^{15}$ passaram a ser desempenhadas, diretamente, pelas superintendências da SEAM, sem que os prefeitos tenham necessidade de utilizar as associações como mecanismos intermediários de articulação.

Diante da falta de apoio financeiro da União e do estado à manutenção das principais linhas de ação das associações microrregionais de municípios, passa-se a exigir que estas entidades procurem caminhos criativos para a complementação da sua receita. Exige-se, também, maior empenho das associações no sentido de buscar fontes alternativas de complementação orçamentária, através de assinaturas de convênios ou contratos que representem recursos financeiros adicionais destinados a criar condições de apoio efetivo das associações às principais atividades demandadas pelas prefeituras da microrregião, bem como realizar projetos na área de planejamento municipal e regional.

A segunda grande dificuldade da estratégia associativista, observada entre os municípios da microrregião estudada, referese ao desinteresse das administrações municipais pela causa associativista.

Embora as atribuições expressas no estatuto da AMMAN evidenciem a ênfase conferida aos aspectos relacionados com o aperfeiçoamento técnico, administrativo, legal e institucional dos municípios, a ação da AMMAN junto aos municípios associados tem se dado, predominantemente, na área técnica. Assim, as principais atividades realizadas pela associação se referem aos serviços prestados pelo Promoto (terraplenagem, nivelamento, abertura de galerias de esgoto, dragagem e retificação de córregos, abertura de vias públicas, conservação de estradas vicinais, etc.), a elaboração e execução de projetos de engenharia e de arquitetura e a prestação de serviços de apoio à realização de obras de engenharia e urbanização, como locação de praças e loteamentos, serviços de topografia, etc.

Os resultados das pesquisas indicaram que os serviços prestados pela AMMAN não são aqueles a que aspiram as administrações dos municípios, cuja maior demanda se concentra nas áreas jurídica e contábil. De fato, apesar de serem fundamentais para o

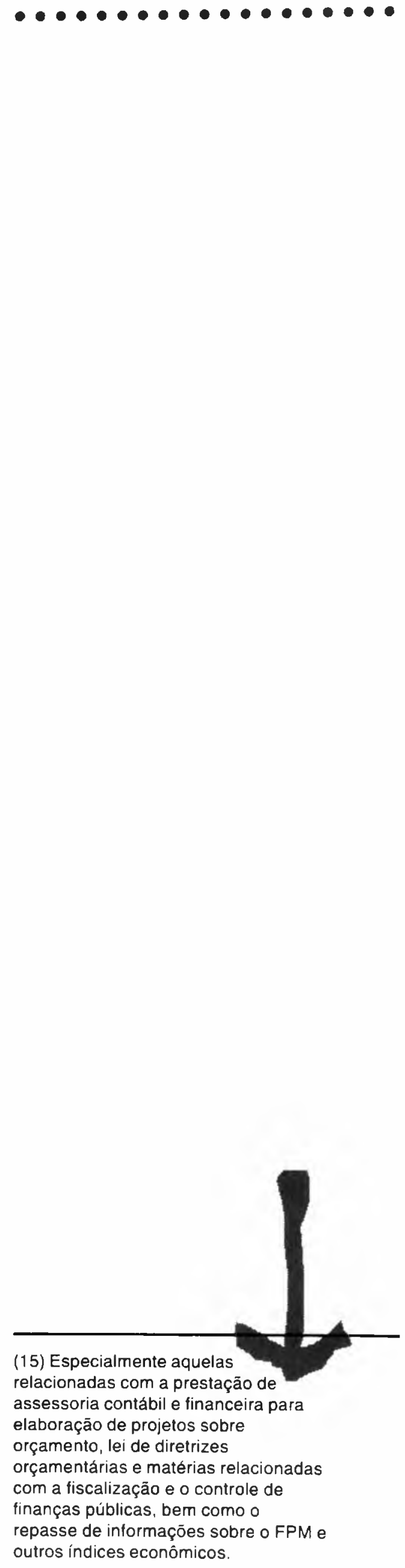


fortalecimento administrativo dos municípios, conforme fica claro através dos estatutos das associações, estas atividades não têm sido contempladas pela AMMAN. O mesmo pode ser observado com relação à elaboração de estudos e levantamentos sobre os problemas e as potencialidades da microrregião, importante tarefa de apoio ao planejamento municipal e microrregional, cuja efetivação poderia gerar benefícios permanentes para os municípios, desempenhando um papel fundamental no desenvolvimento da microrregião. Só nos últimos anos, a AMMAN tem desenvolvido ações no sentido de fortalecer administrativamente os municípios.

No tocante às atividades relativas ao planejamento municipal e ao fortalecimento dos recursos humanos das prefeituras, observase o desinteresse dos dirigentes municipais por atividades cujos resultados não são imediatos. $O$ aperfeiçoamento administrativo dos servidores municipais foi tentado diversas vezes pela AMMAN, através de cursos ministrados mediante convênios estabelecidos com a Fundação João Pinheiro ou com a Universidade Federal de Viçosa. Porém, a baixa freqüência registrada e a alegação de que as despesas de translado e alimentação do servidor municipal não poderiam ser arcadas pelas prefeituras demonstram o desinteresse ou o descrédito dos administradores municipais por este tipo de atividade.

Mesmo que a AMMAN, assessorada pela Fundação João Pinheiro ou pela Universidade Federal de Viçosa, tenha condições técnicas de apoiar os municípios da microrregião no tocante a atividades relacionadas com a elaboração ou atualização dos principais instrumentos de legislação municipal (como Código de Obras, Lei de Loteamento, Lei de Uso do Solo, Código Tributário Municipal, etc.) e com a realização de atividades de apoio ao planejamento municipal e microrregional (como realização de levantamentos cadastrais, banco de dados, etc.), tem sido inexpressiva a demanda por este tipo de serviços entre os municípios da microrregião.

Apenas os benefícios decorrentes das atividades do Promoto são apontados pelos prefeitos da microrregião como importantes atividades desenvolvidas pela AMMAN junto aos seus municípios. Os possíveis benefícios decorrentes do Escritório de Engenharia e da Central de Processamento de Dados/Gráfica não são percebidos, pela maioria destes prefeitos, como importantes 
atividades de apoio à administração municipal. A pequena procura pelos serviços prestados por este setor da AMMAN, relativos ao IPTU e à organização de cadastros ou orçamentos, e a falta de apoio ao projeto de criação do Banco de Dados Regionais (importante atividade de apoio ao planejamento municipal), ilustram a pequena importância conferida pelas administrações municipais a atividades cujos resultados refletir-se-ão em gestões futuras, demonstrando a visão imediatista dos dirigentes municipais, cujas ações se medem, sobretudo, em função do peso ou do ônus político que possam vir a representar.

Quanto ao estabelecimento da articulação intermunicipal, concluise que o papel da AMMAN, como entidade responsável pela criação e consolidação de uma consciência microrregional, não se tem efetivado na prática. A associação não tem conseguido despertar o "espírito associativista" entre os administradores dos municípios associados, de modo que não existe, de fato, uma "comunhão" de interesses, mas uma "reunião" de interesses heterogêneos. Deste modo, os municípios associados não se fortalecem através da associação, porque seus administradores não acreditam na força da cooperação intermunicipal.

A rigor, a criação do "espírito associativista" exigiria uma associação politica e financeiramente forte. Assim, não há como criar um espírito associativista entre os municípios se, uma vez coligados através de uma associação, esta união não gerar benefícios mais visíveis do que aqueles obtidos por intermédio de um deputado estadual ou de qualquer outra influência política. Considerando-se, ainda, que as administrações municipais mudam a cada 4 anos, é importante que a atuação da associação municipal gere benefícios visíveis aos municípios, garantindo à próxima gestão, a credibilidade na associação, consolidando a confiança no poder da união intermunicipal, até que esta confiança se solidifique e se transforme numa tradição política, como tantas outras já estabelecidas.

A falta de "espírito associativista" entre os administradores dos municípios associados prejudica o desempenho da AMMAN, tanto no que diz respeito ao fortalecimento técnico, administrativo e institucional dos municípios quanto no que se relaciona com a articulação intergovernamental, pois se esvazia de conteúdo o próprio associativismo, cuja força maior reside na força de união entre os municípios.

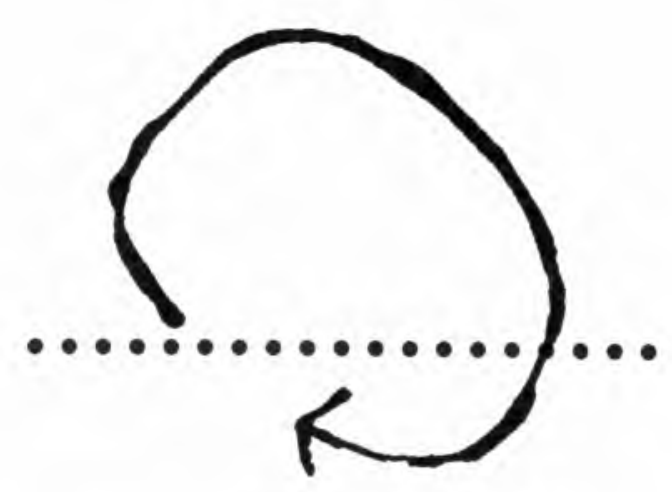


Quanto à articulação intergovernamental, confirmando os resultados de pesquisas e relatórios realizados pelos órgãos do Sistema Estadual de Planejamento de Minas Gerais, os questionários respondidos pelos prefeitos da microrregião estudada, bem como pelos técnicos entrevistados, indicaram que a função de articulação intergovernamental prevista pelo associativismo municipal não se efetivou, na prática.

No caso específico da microrregião da zona da mata norte, a articulação intergovernamental não passou além das tentativas dos secretários executivos e dos presidentes da AMMAN no sentido de criar um canal de articulação com outros níveis de governo, através da participação de autoridades ou de representantes de órgãos estaduais nas assembléias realizadas. Em geral, este processo de articulação se esgotava nas próprias reuniões, isto é, não tinha continuidade, e as questões discutidas acabavam não se traduzindo em ações concretas, nem por parte dos representantes do governo estadual e nem por parte dos governos municipais, quando se necessitava da contrapartida deste nível de governo.

A falência da função de articulação pode ser atribuída a diversos aspectos, relacionados tanto com o contexto político no qual esta estratégia se insere, quanto com o papel efetivo desempenhado pelos órgãos encarregados da sua proposição, implantação e execução no estado.

Quanto ao aspecto relacionado com o contexto histórico e político, no qual o associativismo se insere, a pesquisa realizada indicou que a articulação intergovernamental não se efetivou, independentemente do modelo político-administrativo adotado (centralizador ou descentralizador).

Apesar de vários textos em defesa da prática associativista apresentarem a cooperação intermunicipal como o meio mais eficiente para suprir as dificuldades de interlocução dos níveis locais frente ao centralismo político-administrativo, na realidade, não era este o sentido da articulação pretendida pelo governo federal ao criar a estrutura institucional que daria apoio à implantação do associativismo municipal.

Acredita-se que a intenção do governo federal, ao criar a estrutura institucional que daria sustentação ao associativismo municipal, 
era estabelecer um canal onde os órgãos institucionalizados funcionassem mais como instâncias asseguradoras das diretrizes preconizadas em nivel federal do que, na realidade, como porta-vozes das necessidades locais. Mesmo que se reconheça a existência dos dois movimentos na essência do associativismo municipal, na prática, privilegiou-se apenas o movimento descendente.

Por outro lado, o contexto de centralização política que caracterizou o momento de criação e implantação da estratégia associativista no estado de Minas Gerais não foi o único responsável pela falência da função de articulação. A pesquisa realizada indicou que o novo contexto político descentralizador não tem sido capaz, por si só, de possibilitar a efetivação desta função. Isto se deve ao fato de que também a descentralização não tem ocorrido no nível desejado. Confundida, na maior parte das vezes, com a desconcentração das atividades administrativas, a descentralização no estado de Minas Gerais não tem passado da abertura ao diálogo e da manutenção de uma ação integrada das secretarias estaduais com os órgãos municipais responsáveis pelos serviços públicos, especialmente os relativos à saúde e educação, repassando-se informações, discutindo-se mecanismos e instrumentos.

Embora se acreditasse que, dentro do contexto decorrente das mudanças constitucionais, as principais demandas municipais emergissem das bases (municípios) em direção aos estados, surgindo um "novo associativismo", a análise do Prodemu demonstra que isto não ocorreu.

No tocante ao papel desempenhado pelos órgãos encarregados da proposição, implantação e execução do associativismo municipal no estado, mesmo que esteja explícito, em nível estadual e microrregional, através dos objetivos da Supam e das associações microrregionais de municípios, a intenção de promover a articulação intermunicipal e intergovernamental, enfatizando o papel dessas entidades como instâncias intermediárias de negociação entre o município e o estado, na prática, esta função não foi privilegiada.

Foi consenso, entre os técnicos entrevistados, que a articulação estado/município talvez só tenha sido atingida nos primeiros momentos da existência das associações, quando a Seplan 
coordenava o processo. Atualmente, o processo não tem se dado nem sequer no sentido descendente.

Os questionários respondidos pelos técnicos também indicaram que a falta de um trabalho articulado entre as Secretarias de Estado de Assuntos Municipais (SEAM/MG) e de Planejamento e Coordenação Geral (Seplan/MG) tem dificultado a coordenação, compatibilização e integração do planejamento municipal com o estadual através das associações. Além disso, o Prodemu não foi assumido pela Seplan como estratégia de governo para integrar o planejamento no âmbito do estado e dos municípios.

Apesar de todas as dificuldades que envolvem a execução do associativismo municipal na microrregião da zona da mata norte, ainda acreditamos que o associativismo pode ser um importante fator de fortalecimento dos governos locais, especialmente tendo em vista a realidade municipal do estado, em que mais de $70 \%$ dos municípios possuem população inferior a 20.000 habitantes e sobrevivem basicamente do Fundo de Participação dos Municípios.

Consideramos, entretanto, que esta estratégia só poderá minimizar as dificuldades financeiras que envolvem os pequenos municípios mineiros se receber apoio efetivo por parte do governo estadual. O fortalecimento das associações municipais, via estado, melhoraria suas condições de atuação, aumentando a confiabilidade dos municípios associados. Conseqüentemente, aumentaria o número de municípios participantes e o montante de contribuição financeira proveniente dos municípios associados, de modo que, num ciclo contínuo, as associações passariam a ter melhores condições financeiras para atender às demandas municipais e adquirir condições próprias de sobrevivência.

Tal raciocínio não significa sugerir a recentralização das atividades de planejamento, mas o entendimento que a política de descentralização não deve representar o afastamento total do estado, mas a redefinição de competências e funções, uma vez que o associativismo municipal foi um mecanismo implantado pelo próprio estado.

Por outro lado, o associativismo municipal em Minas Gerais pode ser um importante fator de fortalecimento municipal se houver, por parte das administrações municipais e da própria comunidade,

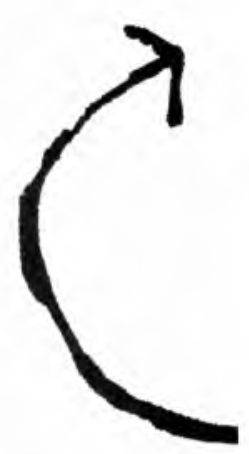


a conscientização da necessidade de um desenvolvimento endógeno e a confiança na cooperação intermunicipal para a solução de seus problemas técnicos e administrativos, aumentando a participação de seus municípios junto às associações.

Se, no passado, as condições políticas impediram que os movimentos ascendente e descendente do processo de planejamento integral contido no associativismo municipal se efetivassem, no momento presente, espera-se, muitas vezes, que o processo se dê apenas no sentido ascendente.

Entende-se, no entanto, que a ação do associativismo municipal só se tornará efetiva se ocorrer a partir de um duplo movimento no qual, através do apoio do estado, haja o fortalecimento das associações, incentivando a participação dos municípios e, a partir daí, o desencadeamento do movimento ascendente, tão importante para qualquer processo de planejamento.

ALVES, llídio. Descentralização: a experiência de Minas Gerais. In: Relatório do Programa Estadual de Descentralização Regional. Porto Alegre: Secretaria do Interior, Desenvolvimento Regional e Obras Públicas - Governo do Estado do Rio Grande do Sul, nov. 1988. p.107-112.

ARANTES, Paulo T. L. A experiência mineira em articulaçāo, assistência técnica e assessoramento a seus municipios através do associativismo municipal, a partir de 1974. São Paulo, 1990. 139p. Dissertação (Mestrado) - Faculdade de Arquitetura e Urbanismo, Universidade de São Paulo.

ASSOCIAÇĀO DE MUNICÍPIOS DA MICRORREGIĀO DA ZONA DA MATA NORTE. Estatuto da Associação dos Municipios da Microrregião da Zona da Mata Norte. Viçosa/MG: AMMAN, 1985. AMMAN, 1985.

Ata de constituição, aprovação e eleição da primeira diretoria. Viçosa/MG

Relatório de atividades: período 1986, 87 e 88. Viçosa/MG: AMMAN, 1988.

CORNELY, Seno A. Evolução do planejamento urbano e local no Brasil - perspectiva microrregional. Revista Planejamento, v. 4, n. 2, p. 97-113, abr./dez. 1976.

DUTRA, Heraldo Santos, DRUMMOND, Vânia Mara F., PIRES, Maria Coeli S. O novo associativismo. In: MINAS GERAIS. Secretaria de Estado de Assuntos Municipais. $O$ associativismo estratégico. Belo Horizonte: SEAM [1992?].

DUTRA, Heraldo S., PIRES, Maria Coeli S. O Associativismo Municipal em Minas Gerais e a presença do Estado. In: MINAS GERAIS. Secretaria de Estado de Assuntos Municipais. $O$ associativismo estratégico. Belo Horizonte: SEAM [1992?].

INFORMATIVO AMMAN. Associativismo Municipal na Microrregião da Zona da Mata Norte. Viçosa, 1992. Edição Especial.

\section{Bibliografia}


JUNQUEIRA, Ana Thereza M. Consórcio intermunicipal: um instrumento de gestão. Revista do CEPAM 2, São Paulo, abr./jun., 1990.

MEIRELLES, Hely L. Autarquias municipais. Rio de Janeiro, Revista de Administração Municipal, v. 9, n. 54, p. 374-384, 1962. 1985. 655p.

Direito municipal brasileiro. 5 ed. São Paulo: Editora Revista dos Tribunais,

MINAS GERAIS. (Estado). Decreto n. 32.790/91. Programa permanente de desenvolvimento municipal: Prodemu. Belo Horizonte, 1991. pela SEAM - $25 \mathrm{p}$.)

Decreto n. 34.559/93. Organização da SEAM. Belo Horizonte, 1993 (compilado

MINAS GERAIS. SEAM/ SEPLAN/ Fundação João Pinheiro/ FEMAM. Programa permanente de desenvolvimento municipal (Prodemu) - Descentralização, participação e fortalecimento dos governos locais. Belo Horizonte: Fundação João Pinheiro, 1991.

Programa Permanente de Desenvolvimento Municipal (Prodemu) - Demandas sistematizadas da associação microrrregional dos municipios do médio Sapucaí (AMESP). Belo Horizonte: Fundação João Pinheiro, 1991. Relatório preliminar. 66p.

. Programa Permanente de Desenvolvimento Municipal (Prodemu)-Articulação com a Secretaria Estadual de Obras Públicas. Belo Horizonte: Fundação João Pinheiro, jul./1992. 39p.

MINAS GERAIS (Cidade). Secretaria de Estado de Assuntos Municipais. Minuta de anteprojeto de estatuto de uma associação microrregional de municipios. Belo Horizonte: SEAM, out. 1992, 23 p.

Fortalecendo o municipio para valorizar o cidadão. Belo Horizonte: SEAM, [19 - - ]. Sem paginação. (Folheto avulso).

PIRES, M. C. S. Os desafios das administraçōes municipais. In: MINAS GERAIS. Secretaria de Estado de Assuntos Municipais. O associativismo estratégico. Belo Horizonte: SEAM [199-].

SOUTO MAIOR, J. A problemática da coordenação, cooperação e planejamento intermunicipais no Brasil. Revista de Administração Municipal, Rio de Janeiro, jul./set. 1992.

TAVARES, Hermes. Planejamento microrregional e consórcios intermunicipais. Revista de Administração Municipal, Rio de Janeiro, v. 24, n. 144, p. 53-64, set./out. 1977. 